\title{
Unlicensed and off label drug use in paediatric wards: prospective study
}

\author{
Sean Turner, Alexandra Longworth, Anthony J Nunn, Imti Choonara
}

\begin{abstract}
Objective: To determine the extent of use in children in hospital of drugs that are not specifically licensed for use in children (unlicensed) and of drugs that are used outside the terms of their product licence that apply to indication, age, dose, or route of administration (off label).

Design: Prospective study of drugs administered on paediatric medical and surgical wards for 13 weeks.

Setting: Regional children's hospital.

Subjects: Paediatric inpatients in medical and surgical wards.

Main outcome measures: Comparison of the use of each drug with its product licence to determine whether the drug was used in an unlicensed or off label manner.

Results: 2013 courses of drugs were administered to 609 paediatric patients in 707 admissions. 506 (25\%) of the drug courses (prescriptions) were either unlicensed (139) or off label (367) uses. In 256 (36\%) of the 707 admissions patients received one or more courses of an unlicensed or off label treatment in hospital.

Conclusions: Use of drugs in an off label or unlicensed manner to treat children is widespread. Drugs are more likely to be used in an off label manner than in an unlicensed manner.
\end{abstract}

\section{Introduction}

Many drugs used to treat children in hospital are either not licensed for use in children (unlicensed) or are being prescribed outside the terms of the product licence (off label prescribing). ${ }^{2}{ }^{2}$ There is considerable interest within the United Kingdom ${ }^{3}$ and the United States ${ }^{45}$ in unlicensed and off label drug use in children, but little information is available on the extent to which these types of treatments are used. We have reported our findings on unlicensed and off label drug use in a paediatric intensive care unit. $^{6}$ We describe our findings on drug treatment in paediatric medical and surgical wards.

\section{Patients and methods}

A medical ward and a surgical ward at this children's hospital were each studied prospectively for 13 weeks between April and August 1996. Data were collected on all patients by the clinical research pharmacist (ST) and the research assistant (AL). The patient's age, date of birth, weight, diagnosis, and all drugs administered, the route of administration, dose, and indication for use were recorded. Use of the following was not recorded: standard intravenous replacement solutions, flushes of sodium chloride $0.9 \%$ or heparin used to maintain the patency of intravenous lines, blood products, oxygen therapy, and topical anaesthetic cream.
All drugs administered were assessed for unlicensed or off label use by ST using a classification system already described. ${ }^{3}$ Categories of unlicensed use included: modifications to licensed drugs (such as dispensing a drug in a different form, for example, crushing tablets to prepare a suspension), drugs that are licensed but the particular formulation is manufactured under a special licence (such as when an adult preparation is not suitable for use in children and a smaller dose must be formulated), new drugs available under a special manufacturing licence (such as caffeine injections for apnoea of prematurity), use of chemicals as drugs, drugs used before a licence has been granted, and imported drugs. The category of off label use included use of a drug in situations not covered by the product licence: administration of a greater dose or more often, administration for indications not described in the licence, administration to children outside the age range for which the product is licensed, the use of alternative routes of administration, and use when the product is contraindicated. The Association of the British Pharmaceutical Industry's Data Sheet Compendium 1995-96 was used as the primary reference source since product licences are not published but are summarised in the datasheet. ${ }^{7}$ If a drug was not included in the compendium, the package insert or the British National Formulary, March 1996 edition, $^{8}$ was used as a secondary reference source. Most of the information published in the British National Formulary conforms to that in a drug's datasheet. If data could not be obtained from any of the reference sources, or if the information was ambiguous, the manufacturer was contacted.

\section{Results}

A total of 609 patients in 707 admissions were included in the study. Of these, $384(63 \%)$ of patients were male; this was due to the greater number of boys admitted for urogenital surgery. The ages of the patients ranged from 4 days to 20 years (median 2 years).

A total of 2013 drug courses (prescriptions) were administered to patients. Patients received between 0 and 21 different drugs. The median number of drugs

Table 1 The 10 drugs most commonly used in paediatric medical and surgical wards

\begin{tabular}{lc} 
Drug & No of prescriptions $(\mathbf{n}=\mathbf{2 0 1 3})$ \\
\hline Paracetamol & 359 \\
\hline Cefotaxime & 120 \\
\hline Diclofenac sodium & 82 \\
\hline Morphine & 80 \\
\hline Salbutamol & 59 \\
\hline Metronidazole & 57 \\
\hline Prednisolone & 53 \\
\hline Cefaclor & 47 \\
\hline Trimethoprim & 39 \\
\hline Lactulose & 39
\end{tabular}

Department of Pharmacy, Alder Hey Children's Hospital, Liverpool L12 2AP

Sean Turner,

clinical research pharmacist Anthony J Nunn, director of pharmacy

Institute of Child Health, Alder Hey Children's Hospital Alexandra

Longworth, research assistant Imti Choonara, senior lecturer in paediatric clinical pharmacology

Correspondence to: Professor Imti Choonara, Academic Division of Child Health, Derbyshire Children's Hospital, Derby DE22 3NE imti.choonara@ nottingham.ac.uk

BMJ 1998;316:343-5 
Table 2 The 10 drugs most commonly used in an unlicensed or off label manner in the paediatric surgical ward

\begin{tabular}{lc} 
Drug & No $(\mathbf{\%})$ of prescriptions $(\mathbf{n}=\mathbf{1 0 5 3})$ \\
\hline Diclofenac sodium & $51(5)$ \\
\hline Morphine & $48(5)$ \\
\hline Oxybutynin & $23(2)$ \\
\hline Paracetamol & $15(1)$ \\
\hline Ranitidine & $12(1)$ \\
\hline Sodium bicarbonate & $6(<1)$ \\
\hline Sucralfate & $6(<1)$ \\
\hline Cisapride & $6(<1)$ \\
\hline Folic acid & $5(<1)$ \\
\hline Klean-Prep & $5(<1)$ \\
\hline
\end{tabular}

Table 3 The 10 drugs most commonly used in an unlicensed or off label manner in the paediatric medical ward

\begin{tabular}{lc} 
Drug & No (\%) of prescriptions $(\mathbf{n}=\mathbf{9 6 0})$ \\
\hline Salbutamol & $33(3)$ \\
\hline Ipratropium bromide & $26(3)$ \\
\hline Folic acid & $24(3)$ \\
\hline Multivitamin drops & $19(2)$ \\
\hline Cisapride & $11(1)$ \\
\hline Paracetamol & $8(<1)$ \\
\hline Frusemide & $7(<1)$ \\
\hline Dill water* & $7(<1)$ \\
\hline Amiloride hydrochloride & $6(<1)$ \\
\hline Total parenteral nutrition & $5(<1)$ \\
\hline
\end{tabular}

*Made in hospital from concentrate. Used to treat babies with colic.

administered was two on the surgical ward and one on the medical ward. The 10 most commonly administered drugs are shown in table 1.

In $506(25 \%)$ of the 2013 prescriptions drugs were used in either an unlicensed (139) or off label manner (367). In 256 admissions patients received one or more drugs in an unlicensed or off label manner during their stay in hospital. Of the 1053 prescriptions written on the surgical ward 64 were for unlicensed uses and 201 were for off label uses. Of the 960 prescriptions written

Table 4 Types and numbers of times drugs used in an off label manner in paediatric surgical and medical wards. Values are numbers of prescriptions (percentages)

\begin{tabular}{lcc} 
& \multicolumn{2}{c}{ Paediatric ward } \\
\cline { 2 - 3 } Type of off label drug use & Surgical $(\mathbf{n}=\mathbf{1 0 5 3})$ & Medical $(\mathbf{n = 9 6 0 )}$ \\
\hline Used in child of inappropriate age & $130(12)$ & $87(9)$ \\
\hline Used for indication different from which it is licensed & $86(8)$ & $14(2)$ \\
\hline Different dose used & $9(1)$ & $80(8)$ \\
\hline Different route of administration & $9(1)$ & $8(1)$ \\
\hline Used when contraindicated & $1(<1)$ & $1(<1)$ \\
\hline Total No off label uses & $235(22)$ & $190(20)$ \\
\hline
\end{tabular}

Table 5 Type and number of times drugs used in an unlicensed manner on the paediatric surgical and medical wards. Values are number of prescriptions (percentages)

\begin{tabular}{lcc} 
& \multicolumn{2}{c}{ Paediatric ward } \\
\cline { 2 - 3 } Type of unlicensed use of drug & Surgical $(\mathbf{n = 1 0 5 3 )}$ & Medical $(\mathbf{n = 9 6 0})$ \\
\hline Special formulation of licensed drug & $35(3)$ & $30(3)$ \\
\hline Modification to licensed drug & $15(1)$ & $16(2)$ \\
\hline New drug available under special manufacturing licence & $5(<1)$ & $11(1)$ \\
\hline Drug made from raw material & $2(<1)$ & $10(1)$ \\
\hline $\begin{array}{l}\text { Imported drug licensed for use in another country but not in } \\
\text { United Kingdom }\end{array}$ & $4(<1)$ & $4(<1)$ \\
\hline Chemical used as drug & $3(<1)$ & $3(<1)$ \\
\hline Drug available only to patients taking part in trial & 0 & $1(<1)$ \\
\hline Total No unlicensed uses & $64(6)$ & $75(8)$ \\
\hline
\end{tabular}

on the medical ward 75 were for unlicensed uses and 166 for off label uses. The drugs most frequently administered in an unlicensed or off label manner are shown in table 2 for the surgical ward and table 3 for the medical ward.

Many drugs were used both according to the terms of the licence and in an off label way. For example, morphine was administered to 80 children. Intravenous morphine is licensed for use in children aged 12 years and older. Thirty two children were eligible to be treated with morphine according to the terms of the product licence, but 48 children were treated with the drug in an off label manner. The number and type of off label or unlicensed uses are shown in tables 4 and 5 respectively. In 58 cases a drug was used in an off label manner for two reasons. Hence, in table 4 the total number of times a drug was used in an off label manner is greater than the total number of off label prescriptions.

\section{Discussion}

The off label and unlicensed use of drugs to treat children is widespread and occurs in medical and surgical wards, as well as in critically ill children. ${ }^{6}$ Off label use occurs considerably more frequently than unlicensed use. Drugs are being used in children at ages for which they have not been licensed and, possibly, evaluated; at doses greater than that recommended by manufacturers; and for indications outside the terms of the product licence. It is not clear whether the use of drugs in these ways is appropriate.

The drugs most commonly used in an off label or unlicensed manner are usually established drugs for which there is a large amount of clinical information available-for example, morphine, paracetamol, salbutamol, ipratropium bromide. When a drug is already extensively used there is no commercial incentive for a pharmaceutical company to seek an amendment to the product licence. The Medicines Control Agency should therefore request an application for a product licence from companies whose products are being used in an off label or unlicensed manner and take into account published paediatric clinical trials and surveillance studies of off label use.

Newer drugs, such as diclofenac sodium and cisapride, are also being used in children. Clinical studies are needed to evaluate the efficacy and toxicity of these drugs in children. In the United States the Food and Drug Administration asks manufacturers to provide additional information on the use of established drugs in paediatric patients and to justify reasons for not performing paediatric studies when new drugs are submitted for licensing. ${ }^{410}$ The publication of the new European guidelines on the clinical investigation of medicinal products in children suggests that a similar approach will now be adopted in Europe. $^{11}$

These new guidelines may result in a change of attitude among the pharmaceutical companies and the regulatory authorities. Clinical trials in children may be more difficult to organise than trials in adults, but they can be organised in children of all ages. ${ }^{12-14}$ Drugs used to treat children must be evaluated scientifically and the regulatory authorities must ensure that this is done. The National Institutes of Health in the United States 
- Children in hospital are often treated with drugs not specifically licensed for use in children (unlicensed), and drugs are also used outside the terms of the product licence that apply to indication, age, dose, or route of administration (off label prescribing)

- In this study $36 \%$ of children in 707 admissions received drugs prescribed in either an unlicensed or off label manner

- Off label drug prescribing was more common than unlicensed drug prescribing

- All drugs used to treat children should be subjected to the licensing process to ensure their quality, safety, and efficacy

- The Medicines Control Agency, the pharmaceutical industry, and the NHS need to address the issue of drugs being used in these ways

has established paediatric pharmacology research units, which has resulted in an increase in the number of clinical trials in children ( $\mathrm{S}$ Yaffe, personal communication, 1997). Each unit is led by an experienced paediatric clinical pharmacologist. The development of a similar approach in the United Kingdom should be encouraged. The establishment of a national centre to study drug treatment in children would increase the number of clinical trials in which children participate. Funding for such a centre should be a priority for the British pharmaceutical industry, the Medicines Control Agency, the NHS, and research charities.
Contributors: IC initiated and designed the study, supervised the collection of data, analysed the data, and was involved in writing the paper. ST designed the data collection forms, coordinated and was involved in collecting and analysing the data, and was involved in writing the paper. AJN initiated and was involved in the design of the study, analysed the data, and was involved in writing the paper. AL helped design the data collection form, helped collect the data, and entered the data on to the computer. Funding: North West Regional Health Authority.

Conflict of interest: None.

1 Choonara I, Nunn T, Hull D. Medicines for children. J Pharm Med 1995;5:96.

2 British Paediatric Association and the Association of the British Pharmaceutical Industry. Licensing medicines for children. Joint report of the British Paediatric Association and the Association of the British Pharmaceutical Industry, 1996. London: BPA, 1996.

3 Turner S, Nunn AJ, Choonara I. Unlicensed drug use in children in the UK. Paediatr Perinat Drug Ther 1997;1:52-5.

4 Nahata MC. Licensing of medicines for children in the USA. Paediatr Perinat Drug Ther 1997;1:50-1.

5 Cotè CJ, Kauffman RE, Troendle GJ, Lambert GH. Is the "therapeutic orphan" about to be adopted? Pediatrics 1996;98:118-23.

6 Turner S, Gill A, Nunn T, Hewitt B, Choonara I. Use of "off-label" and unlicensed drugs in paediatric intensive care unit. Lancet 1996;347: $549-50$.

7 Association of the British Pharmaceutical Industry. ABPI data sheet compendium 1995-96. London: Datapharm Publications, 1995.

8 British Medical Association and the Roval Pharmaceutical Society of Great Britain. British national formulary. No 31. London: BMA, RPSGB, 1996.

9 Kauffman RE. Status of drug approval processes and regulation of medications for children. Curr Opinion Pediatr 1995;7:195-8.

10 Cotè CJ. Sedation for procedures in children. Paediatr Perinat Drug Ther 1997;1:3-8.

11 European Agency for the Evaluation of Medicinal Products. Note for guidance on clinical investigation of medicinal products in children. London: EAEMP, 1997.

12 Cornelissen EAM, Kollee LAA, De Abreu RA, Motohara K, Monnens $\mathrm{LAH}$. Effects of oral and intramuscular vitamin $\mathrm{K}$ prophylaxis on vitamin $\mathrm{K}_{1}$, PIVKA-II and clotting factors in breast fed infants. Arch Dis Child 1992;67:1250-4.

13 Benini F, Johnston C, Faucher D, Aranda JV. Topical anesthesia during circumcision in newborn infants. JAMA 1993;270:850-3.

14 Parkinson L, Hughes J, Gill A, Billingham I, Ratcliffe J, Choonara I. A randomised controlled trial of sedation in the critically ill. Pediatr Anesth 1997;7:405-10.

(Accepted 23 September 1997)

\title{
Clinical experience, performance in final examinations, and learning style in medical students: prospective study
}

\author{
I C McManus, P Richards, B C Winder, K A Sproston
}

\begin{abstract}
Objective: To assess whether the clinical experience of undergraduate medical students relates to their performance in final examinations and whether learning styles relate either to final examination performance or to the extent of clinical experience. Design: Prospective, longitudinal study of two cohorts of medical students assessed by questionnaire at time of application to medical school and by questionnaire and university examination at the end of their final clinical year.

Subjects: Two cohorts of students who had applied to St Mary's Hospital Medical School during 1980 $(\mathrm{n}=1478)$ and $1985(\mathrm{n}=2399)$ for admission in 1981 and 1986 respectively. Students in these cohorts who entered any medical school in the United Kingdom were followed up in their final clinical year in 1986-7 and 1991-2.
\end{abstract}

\begin{abstract}
Main outcome measures: Students' clinical experience of a range of acute medical conditions, surgical operations, and practical procedures as assessed by questionnaire in the final year, and final examination results for the students taking their examinations at the University of London.

Results: Success in the final examination was not related to a student's clinical experiences. The amount of knowledge gained from clinical experience was, however, related to strategic and deep learning styles both in the final year and also at the time of application, five or six years earlier. Grades in A level examinations did not relate either to study habits or
\end{abstract} to clinical experience. Success in the final examination was also related to a strategic or deep learning style in the final year (although not at time of entry to medical school).

Conclusions: The lack of correlation between examination performance and clinical experience 